\title{
Personal Knowledge Management to Enhance the Effectiveness of Teacher Learning Management in Lao PDR
}

\author{
Vathanavanh Sayasane $^{1}$, Kanokorn Somprach ${ }^{1} \&$ Jatuphum Ketchatturat $^{2}$ \\ ${ }^{1}$ Department of Educational Administration, Faculty of Education, Khon Kaen University, Thailand \\ ${ }^{2}$ Department of Educational Measurement and Evaluation, Faculty of Education, Khon Kaen University, Thailand \\ Correspondence: Kanokorn Somprach, Department of Educational Administration, Faculty of Education, Khon \\ Kaen 40002, Thailand. Tel: 66-881166995. E-mail: kanoklin@kku.ac.th
}

Received: June 7, 2021; Accepted: June 20, 2021; Published: June 23, 2021

\begin{abstract}
This study was intended to search the vital factors and indicators of personal knowledge management and the effectiveness of teacher learning management for primary school teachers in Lao PDR. A survey research design was employed to 600 teachers with the purpose of testing the goodness-of-fit of the identified vital factors and indicators with the empirical data. The results revealed that an entire of 30 indicators were recognized from 10 vital factors. The structural relationship model of personal knowledge management to enhance the effectiveness of teacher learning management indicators was found to be in parallel to the empirical data, with $\chi^{2}=382.319$, $\mathrm{df}=342, \chi \mathrm{I}^{2} \mathrm{df}=1.117, \mathrm{CFI}=0.997, \mathrm{TLI}=0.996, \mathrm{RMSEA}=0.030$, and $\mathrm{SRMR}=0.030$. The results contribute significantly to knowledge with orientation to recommending a measurement model which can be referred by primary school teachers in Lao PDR in particular on how to utilize personal knowledge management skills to enhance their learning management capabilities.
\end{abstract}

Keywords: effectiveness of teacher learning management, indicators, personal knowledge management, primary school teachers, vital factors

\section{Introduction}

Personal knowledge management is started by the individuals (Ismail \& Ahmad, 2011) because knowledge creation begins with individuals (Dalkir, 2011). Therefore, Sondari (2013) supported the importance to understand how individuals manage their knowledge at the personal level. Ha (2017) defined personal knowledge management (PKM) as an innovative concept to supports students to succeed in their individual career aims and academic interests. According to Garner (2010), the exercise of PKM on their personal learning permits students to update and improve personal knowledge systems, upsurge competitive power, and acclimate to the emerging knowledge economy era. Subsequently, Smedley (2009) highlighted the significance of exploring PKM that can contribute to human cognitive capabilities.

$\mathrm{Ha}$ (2017) considered PKM as a conceptual framework to establish and integrate information that students feel is important so that it develops part of their personal knowledge base. In other words, PKM stipulates an approach for transforming what might be random pieces of information into something that can be systematically applied and that develops students' personal knowledge (Grundspenkis, 2007). In this line of reasoning, Garner (2010) suggested that students need to organize their learning materials in a functional manner, in effect managing their personal knowledge because of the vast amounts of information that students have to collect while learning.

Desta, Chalchisa, and Lemma (2013) emphasized the importance of teacher learning management to enhance their cognitive knowledge and skills through professional learning community activities. This is because professional learning community activities provided teachers learn from the best practice if they learned and shared their knowledge and experiences in developing learning management continually. Teachers learned the concepts of learning management for enhancing cognitive skills from workshops or seminars. Teachers applied the concepts in the classroom, they learned more when they shared with other teachers.

The main purpose of this study was to identify the vital factors and indicators of PKM and the effectiveness of teacher learning management in primary schools of Lao PDR. This was followed by testing the goodness-of-fit of the PKM to enhance the effectiveness of the teacher learning management model (PKM\&TLM model) for both factors and indicators with empirical data. This is ultimately supported the primary school administrators to focus 
on vital factors and indicators of teachers' personal knowledge management in order to enhance teacher learning management capabilities.

\section{Method}

\subsection{Research Design, Instrument, and Procedure}

The researchers began their study using survey research design to examine the structural creation between experimental tests and the hypothetical theory of quantitative relationships regarding empirical data. A questionnaire consisted of 153 items was used as an instrument to collect data. The relations are characterized by path coefficients or deterioration between factors and indicators of both variables, namely personal knowledge management (PKM) and effectiveness of teacher learning management (TLM). Figure 1 illustrates the research procedure.

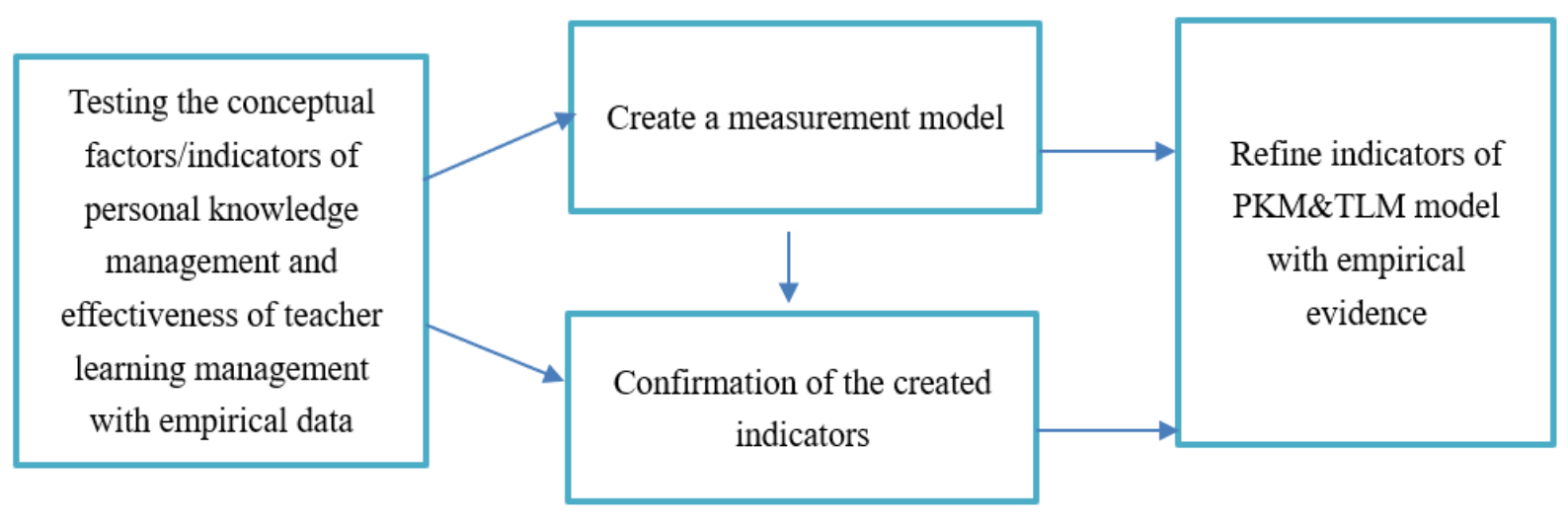

Figure 1. Research Procedure

\subsection{Population and Samples}

The research population consisted of 3444 primary school teachers in Vientiane, Lao PDR. A total of 600 samples were selected using stratified random sampling. The researchers followed the rules of thumb proposed by Meyers, Gamst, and Guarino (2006) and Marsh, Hau, Balla, and Grayson (1998) to decide an adequate sample side in order to apply Structural Equation Modelling (SEM). According to Meyers et al. (2006), suitable sample size depends upon the number of items available for factor analysis. However, Marsh et al. formulated an adequate sample size are recognized as presence of controlled practice in attaining an acceptable probability for the mandatory empirical consequences, for example, model convergence, statistical precision, statistical power for a specific request of confirmatory factor analysis (CFA) with actual data.

\subsection{Data Analysis}

SEM was utilized to analyze the collected data because it is the most suitable technique to analyze the structural relationship between measured variables and latent constructs. Gay, Mills, and Airasian (2011) explained that the SEM is a method used to syndicate factor loading examination and path analysis or multiple regression examination. Moreover, SEM can estimate the multiple and interrelated dependence in a single analysis, namely endogenous and exogenous variables. In this study, the effectiveness of TLM is the endogenous variable while the conceptualized factors and indicators of PKM are the exogenous variables. Consequently, researchers utilized the SEM technique to assess how precisely a measurement model fits the empirical data to examine the appropriateness of the measurement model. The measurement model implies the hypothesis that represents how identified factors and indicators intersect together in corresponding to the hypothesis. Hence, researchers utilized the CFA to test the measurement model for its goodness-of-fit.

\section{Results}

\subsection{General Profile of Samples}

A total of 600 respondents who are holding a bachelor's degree participated in this study. This reflects the general attribute in the teaching profession due to gender differences in occupational preferences and social roles (National Center for Education Statistics, May 2021). The majority of respondents are aged between 31 to 40 years old (77.7\%) and having working experience within 5 to 10 years $(77.8 \%)$. Table 1 shows the distribution of the respondents and their factor demographics. 
Table 1. Distribution of the samples

\begin{tabular}{lcc}
\hline General Profile & Frequency & Percent \\
\hline Gender & & \\
\hline Male & 51 & 8.5 \\
Female & 549 & 91.5 \\
\hline Age & & \\
\hline$<30$ years old & 118 & 19.7 \\
31 to 40 years old & 466 & 77.7 \\
$>41$ years old & 16 & 2.7 \\
\hline Years of experience & & \\
\hline$<5$ years & 117 & 19.5 \\
5 to 10 years & 467 & 77.8 \\
$>10$ years & 16 & 2.7 \\
\hline Total & 600 & 100 \\
\hline
\end{tabular}

\subsection{Exploration of Fitness of Data for Factor Analysis}

The researchers began to explore the fitness of data for factor analysis before attaining estimations of the parameters of the composition of PKM and effectiveness of TLM. Two crucial matters ought to consider before researchers decide whether the attained data is appropriate for CFA, namely the strength of the relationship between factors/indicators and sample size (Pallant, 2013). Researchers utilized Kaiser-Meyer-Olkin (KMO) (Kaiser, 1974) to confirm the required sample size and Bartlett's Test of Sphericity (Bartlett, 1954) to determine the strength of the relationship between the factors/indicators. A large sample size is generally useful although the chi-square $\left(\chi^{2}\right)$ is accepted as a standard statistic to estimate the general fit of the measurement model with the empirical data (Jöreskog \& Sörbom, 1993).

There are several rules of thumb proposed by some experts to decide the acceptable level of KMO value as the measurement to validate the sufficiency of sample size such as Kaiser (1974) and Field (2000) recommended the acceptable KMO value must be more than 0.5 but Pallant (2013) suggested the KMO value should be more than 0.6. Finally, the researchers utilized Hutcheson and Sofroniou's (1999) rule of thumb to interpret the acceptable level of KMO value as shown in Table 2.

Table 2. KMO value and its interpretation

\begin{tabular}{cc}
\hline KMO Value & Interpretation \\
\hline$<0.5$ & Unacceptable sample size \\
0.5 to 0.7 & Average sample size \\
0.7 to 0.8 & Good sample size \\
0.8 to 0.9 & Great sample size \\
$>0.9$ & Excellent sample size \\
\hline
\end{tabular}

Results of the KMO value in Table 3 show that the sampling size is sufficient and excellent because all the KMO values of factors and indicators are above 0.9 (Hutcheson \& Sofroniou, 1999; Pallant, 2013). Besides, Table 3 also shows that obtained data were nearly multivariate normal according to the result of Bartlett Test of Sphericity, and an excellent sample size was obtained as reflected in KMO value (Hutcheson and Sofroniou, 1999). Therefore, the obtained data could proceed for further examination. 
Table 3. Results of validation of the correlation matrix between factors and indicators

\begin{tabular}{ccc}
\hline Factors/Indicators & KMO & $\begin{array}{c}\text { Bartlett's } \\
\text { test }\end{array}$ \\
\hline Intercorrelation analysis of PKM factors/indicators & 0.910 & $p=0.00$ \\
\hline $\begin{array}{c}\text { Intercorrelation analysis of the effectiveness of TLM } \\
\text { factors/indicators }\end{array}$ & 0.910 & $p=0.00$ \\
\hline
\end{tabular}

\subsection{Identification of the Constructs of PKM and the Effectiveness of TLM}

The researchers used factor loading to examine the validity of the observable factors of PKM and the effectiveness of TLM. Hence, researchers could obtain estimates of the parameters of the PKM to enhance the effectiveness of the TLM model. The factor loading refers to the importance of the standard indicators of each factor in the PKM to enhance the effectiveness of the TLM model, that had been taken into account.

Table 4 indicates the factor loading of all the PKM factors ranged from 0.719 to 0.993 and are statistically significant at 0.01 . Moreover, the co-variance with the PKM factors ranged from 55.40 to 98.70 percent. The factor with the highest factor loading was knowledge management and storage (PKM2). This was followed by factors of searching for knowledge (PKM1), knowledge exchange (PKM3), and data analysis (PKM4). The factor that had the lowest factor loading was application and publishing (PKM5). Therefore, the researchers concluded that all the vital factors are found to be key constructs of PKM.

Table 4. Factor loading of PKM

\begin{tabular}{lcccc}
\hline \multicolumn{1}{c}{ Factor } & $\begin{array}{c}\text { Factor } \\
\text { loading }(\beta)\end{array}$ & SE & t-value & $\begin{array}{c}\text { Prediction } \\
\text { coefficient }\left(\mathrm{R}^{2}\right)\end{array}$ \\
\hline Searching for knowledge (PKM1) & 0.842 & 0.021 & 39.257 & 0.708 \\
Knowledge management and storage (PKM2) & 0.993 & 0.020 & 50.920 & 0.987 \\
Knowledge exchange (PKM3) & 0.822 & 0.016 & 51.375 & 0.801 \\
Data analysis (PKM4) & 0.744 & 0.024 & 30.626 & 0.554 \\
Applications and publishing (PKM5) & 0.719 & 0.017 & 42.294 & 0.642 \\
\hline
\end{tabular}

On the other hand, the factor loading of all the effectiveness of TLM was found statistically significant at 0.01 and ranged from 0.734 to 0.977 as illustrated in Table 5. Meanwhile, the co-variance with the effectiveness of TLM factors varied from 53.90 to 95.50 percent and considered key constructs of the effectiveness of TLM. The details of results in descending order are as follows: Learning management in specific content (TLM2), teacher professionalism (TLM3), innovation in learning management (TLM4), learning assessment (TLM5), and course administration and management (TLM 1).

Table 5. Factor loading of the effectiveness of TLM

\begin{tabular}{lcccc}
\hline \multicolumn{1}{c}{ Factor } & $\begin{array}{c}\text { Factor } \\
\text { loading }(\beta)\end{array}$ & SE & t-value & $\begin{array}{c}\text { Prediction } \\
\text { coefficient }\left(\mathrm{R}^{2}\right)\end{array}$ \\
\hline Course administration and management (TLM 1) & 0.734 & 0.028 & 25.830 & 0.539 \\
Learning management in specific content (TLM2) & 0.977 & 0.015 & 65.862 & 0.955 \\
Teacher professionalism (TLM3) & 0.951 & 0.015 & 64.416 & 0.904 \\
Innovation in learning management (TLM4) & 0.913 & 0.016 & 56.879 & 0.833 \\
Learning assessment (TLM5) & 0.825 & 0.020 & 42.114 & 0.680 \\
\hline
\end{tabular}

After the identification of the vital factors of PKM and effectiveness of TLM, researchers continued to investigate those indicators that derived from the respective factors with regards to fit the Thai context. Table 6 and Table 7 display the details of the empirical results. 
Table 6. Factor loading of PKM indicators

\begin{tabular}{llccc}
\hline Indicators & $\begin{array}{l}\text { Factor } \\
\text { loading } \\
(\beta)\end{array}$ & SE & t-value & $\begin{array}{c}\text { Prediction } \\
\text { coefficient } \\
\left(\mathrm{R}^{2}\right)\end{array}$ \\
\hline PKM 1 Searching for knowledge & & & & \\
\hline PKM 1.1 Access to Information & 0.405 & 0.018 & 22.368 & 0.653 \\
PKM 1.2 Data collection & 0.424 & 0.017 & 24.446 & 0.710 \\
PKM 1.3 Electronic storage and search & 0.443 & 0.018 & 24.639 & 0.740 \\
\hline PKM 2 Knowledge management and storage & & & & \\
\hline PKM 2.1 Categorization & 0.431 & 0.016 & 26.508 & 0.761 \\
PKM 2.2 Organized storage & 0.444 & 0.016 & 27.927 & 0.815 \\
PKM 2.3 Database preparation & 0.443 & 0.018 & 24.583 & 0.696 \\
\hline PKM 3 Knowledge exchange & & & & \\
\hline PKM 3.1 Learning network & 0.445 & 0.022 & 20.227 & 0.643 \\
PKM 3.2 Cooperation exchange & 0.421 & 0.019 & 22.157 & 0.618 \\
PKM 3.3 Publication of work & 0.342 & 0.010 & 34.200 & 0.582 \\
\hline PKM 4 Data analysis & & & & \\
\hline PKM 4.1 Separating knowledge from data & 0.464 & 0.016 & 28.179 & 0.924 \\
PKM 4.2 Data processing & 0.366 & 0.016 & 22.478 & 0.654 \\
PKM 4.3 Knowledge building & 0.285 & 0.018 & 15.876 & 0.364 \\
\hline PKM 5 Applications and publishing & & & & \\
\hline PKM 5.1 Utilizing knowledge & 0.506 & 0.023 & 22.131 & 0.631 \\
PKM 5.2 Information preparation & 0.528 & 0.021 & 25.514 & 0.793 \\
PKM 5.3 Problem-solving and decision making & 0.424 & 0.019 & 21.877 & 0.626 \\
\hline
\end{tabular}

Table 7. Factor loading of the effectiveness of TLM indicators

\begin{tabular}{lllll}
\hline Factor & $\begin{array}{l}\text { Factor } \\
\text { loading }(\beta)\end{array}$ & SE & t-value & $\begin{array}{l}\text { Prediction } \\
\text { coefficient }\left(\mathrm{R}^{2}\right)\end{array}$ \\
\hline TLM 1 Course administration and management & & & & \\
\hline TLM 1.1 Determination of objectives & 0.336 & 0.025 & 13.593 & 0.295 \\
TLM 1.2 Measurement and evaluation & 0.386 & 0.021 & 18.497 & 0.522 \\
TLM 1.3 Curriculum implementation in learning & 0.418 & 0.019 & 21.641 & 0.678 \\
management & & & & \\
\hline TLM 2 Learning management in specific content & & & & \\
\hline TLM 2.1 Effective teaching technique & 0.415 & 0.020 & 20.591 & 0.555 \\
TLM 2.2 Quality learning management plan & 0.441 & 0.020 & 22.359 & 0.627 \\
TLM 2.3 Activities meet students' abilities & 0.477 & 0.019 & 24.733 & 0.713 \\
\hline TLM 3 Teacher professionalism & & & & \\
\hline TLM 3.1 Content knowledge & 0.449 & 0.018 & 24.569 & 0.703 \\
TLM 3.2 Teaching skills & 0.435 & 0.018 & 24.040 & 0.683 \\
TLM 3.3 Research for development & 0.451 & 0.018 & 24.674 & 0.704 \\
\hline TLM 4 Innovation in learning management & & & & \\
\hline TLM 4.1 Creating innovation in class & 0.462 & 0.018 & 25.428 & 0.723 \\
TLM 4.2 Innovation development & 0.440 & 0.019 & 22.879 & 0.632 \\
TLM 4.3 Supplying media technology & 0.478 & 0.019 & 24.600 & 0.699 \\
\hline TLM 5 Learning assessment & & & & \\
\hline TLM 5.1 Reflection of learning outcomes & 0.473 & 0.018 & 26.125 & 0.763 \\
TLM 5.2 Assessment of competence & 0.478 & 0.018 & 26.120 & 0.761 \\
TLM 5.3 Assessment development & 0.428 & 0.025 & 17.407 & 0.417 \\
\hline
\end{tabular}

\subsection{Goodness-of-Fit the PKM to Enhance the Effectiveness of TLM Indicators with the Empirical Data}

The PKM to enhance the effectiveness of the TLM model is depending on the fit indices to decide the acceptance of the SEM model (Ullman, 2001). The following tests were employed to determine how to relate real values are fitting to the expected values in the SEM model as shown in Table 8. In this line of reasoning, researchers referred 
to the following experts' rules of thumb and their recommended cut-off values for evaluating fit indices in the SEM model.

Table 8. Interpretation of Goodness-of-fit indexes for PKM to enhance the effectiveness of TLM model

\begin{tabular}{|c|c|c|c|c|}
\hline $\begin{array}{l}\text { Goodness- } \\
\text { of fit } \\
\text { Indexes }\end{array}$ & $\begin{array}{l}\text { Real } \\
\text { values }\end{array}$ & $\begin{array}{l}\text { Rules of thumb or } \\
\text { cut-off values }\end{array}$ & Specialists & Interpretation \\
\hline$\chi^{2 / d f}$ & 1.2975 & $\begin{array}{l}<2 \\
<5\end{array}$ & $\begin{array}{l}\text { Ullman (2001) } \\
\text { Schumacker and Lomax (2004) }\end{array}$ & Pass \\
\hline $\begin{array}{l}\text { CFI } \\
\text { GFI } \\
\text { AGFI }\end{array}$ & 0.99 & $\begin{array}{l}\geq 0.95 \\
\mathrm{CF}=0.95 \\
\geq 0.90\end{array}$ & $\begin{array}{l}\mathrm{Hu} \text { and Bentler (1999) } \\
\text { Diamantopoulos and Siguaw (2000) }\end{array}$ & Pass \\
\hline TLI & 0.99 & $\geq 0.95$ & Hu and Bentler (1999) & Pass \\
\hline RMSEA & 0.02 & $\begin{array}{l}<0.06 \\
<0.07\end{array}$ & $\begin{array}{l}\text { Hu and Bentler (1999) } \\
\text { Steiger (2007) }\end{array}$ & Pass \\
\hline SRMR & 0.01 & $<0.05$ & $\begin{array}{l}\text { Byrne (1998); } \\
\text { Diamantopoulos and Siguaw (2000) }\end{array}$ & Pass \\
\hline
\end{tabular}

The result revealed that the PKM to enhance the effectiveness of TLM model has a goodness of fit with the obtained data, with $\chi^{2}=382.319, \mathrm{df}=342, \chi \rho^{2} \mathrm{df}=1.117, p$-value $=0.0655, \mathrm{CFI}=0.997, \mathrm{TLI}=0.996, \mathrm{RMSEA}=$ 0.030 , and SRMR $=0.030$. Therefore, it was found that the PKM to enhance the effectiveness of the TLM model congruent with the empirical data.

\subsection{Direct Effect, Indirect Effect, and Overall Effect of the PKM to Enhance the Effectiveness of TLM}

The results of direct effect, indirect effect as well as the overall effect of the PKM factors enhancing the effectiveness of TLM indicated that there is a significant direct effect at the level of 0.01 as shown in Table 9 below.

Table 9. Direct effect, indirect effect, and overall effect of PKM to enhance the effectiveness of TLM

\begin{tabular}{lccc}
\hline Causal Factor & \multicolumn{3}{c}{ Effectiveness of TLM } \\
\hline & Direct Effect & Indirect Effect & Total Effect \\
\hline PKM & $0.742^{* *}$ & - & $0.742^{* *}$ \\
SE & & 0.049 & \\
t-value & 15.142 & \\
$\mathrm{R}^{2}$ & 0.752 & \\
\hline \multicolumn{2}{c}{$\chi^{2}=382.319, \mathrm{df}=342, \chi \rho^{2} \mathrm{df}=1.117, \mathrm{CFI}=0.997, \mathrm{TLI}=0.996, \mathrm{RMSEA}=0.030$, and SRMR $=0.030$} \\
\hline$* * 01$
\end{tabular}

\section{Discussion}

The significant results of this study are related to the status of the standard factor loading of every factor in the PKM to enhance the effectiveness of the TLM model. These results were supported by Tuksino (2009) who revealed that all the recognized factors and indicators of the measurement model conformed perfectly at a significant level of 0.01 with the empirical data. As a result, researchers concluded that all the 10 vital factors and their 30 indicators are important variables and seem to be in corresponding to both theory and literature review.

Moreover, the results demonstrated that the goodness-of-fit index (GFI) of the PKM to enhance the effectiveness of TLM model, trailed by the selected measures, discovered a structural relationship between the personal knowledge management and learning management of the primary school teachers with the empirical data. Conclusively, researchers want to recommend to the Laos Ministry of Education that they ought to include the personal knowledge management skills development approach of this study in the teaching professional training program for the future. 


\section{Acknowledgments}

The authors gratefully acknowledge the use of service and facilities of the Faculty of Education, Khon Kaen University, Khon Kaen 40002, Thailand. The contents of this manuscript are derived from the first author's doctoral dissertation thus fulfilling the Ph.D. requirement of Khon Kaen University.

\section{References}

Bartlett, M. S. (1954). A note on the multiplying factors for various chi square approximation. Journal of Royal Statistical Society, 16(Series B), 296-298. https://doi.org/10.1111/j.2517-6161.1954.tb00174.x

Byrne, B. M. (1998). Structural equation modeling with LISREL, PRELIS and SIMPLIS: Basic concepts, applications and programming. Mahwah, NJ: Lawrence Erlbaum Associates.

Dalkir, K. (2011). Knowledge management in theory and practice (2nd ed.). Cambridge, MA: Massachusetts Institute of Technology.

Desta, D., Chalchisa, D., \& Lemma, G. (2013). School-based continuous teacher professional development in an investigation of practices, opportunities and challenges. Journal of International Cooperation in Education, 15(3), 77-94.

Diamantopoulos, A., \& Siguaw, J. A. (2000). Introducing LISREL. London, UK: Sage. https://doi.org/10.4135/9781849209359

Field, A. (2000). Discovering statistics using SPSS for Windows. London, UK: Sage.

Garner, S. (2010). Personal knowledge management and student learning. Journal of Business \& Economics Research, 8(12), 43-48. https://doi.org/10.19030/jber.v8i12.779

Gay, L. R., Mills, G. E., \& Airasian, P. W. (2011). Educational Research. New Jersey: Pearson Education.

Grundspenkis, J. (2007). Agent based approach for organization and personal knowledge modelling: Knowledge management perspective. Journal of Intelligence Manufacturing, 18(4), 451-457. https://doi.org/10.1007/s10845-007-0052-6

Ha, N. H. (2017). The impact of personal knowledge management on learning outcome. International Journal of Learning and Teaching, 3(2), 101-105. https://doi.org/10.18178/ijlt.3.2.101-105

Hu, L. T., \& Bentler, P. M. (1999). Cut-off criteria for fit indexes in covariance structure analysis: Conventional criteria versus new alternatives. Structural Equation Modeling, 6(1), 1-55. https://doi.org/10.1080/10705519909540118

Hutcheson, G. D., \& Sofroniou, N. (1999). The multivariate social scientist: An introduction to generalized linear models. London, UK: Sage. https://doi.org/10.4135/9780857028075

Ismail, S., \& Ahmad, M. S. (2011). Personal knowledge management among researchers: Knowing the knowledge expert. In Proceeding of the $10^{\text {th }}$ International Research Conference on Quality, Innovation and Knowledge Management, 15-18 February, Kuala Lumpur, Malaysia.

Jöreskog, K., \& Sörbom, D. (1993). LISREL 8: Structural equation modelling with the SIMPLIS command language. Chicago, IL: Scientific Software International Inc.

Kaiser, H. (1974). An index of factorial simplicity. Psychometrika, 39, 31-36. https://doi.org/10.1007/BF02291575

Marsh, H. W., Hau, K. T., Balla, J. R., \& Grayson, D. (1998). Is more ever too much? The number of indicators per factor in confirmatory factor analysis. Multivariate Behavioral Research, 33, 181-220.

Meyers, L. S., Gamst, G., \& Guarino, A. J. (2006). Applied multivariate research: Design and interpretation. Thousand Oaks, CA: Sage

National Center for Education Statistics. (May 2021). Characteristics of public-school teachers. Annual Report and Information Staff. Retrieved from https://nces.ed.gov/programs/coe/indicator/clr

Pallant, J. (2013). SPSS survival manual: A step by step guide to data analysis using SPSS (4th ed.). New South Wales, Australia: Allen \& Unwin. https://doi.org/10.1080/00396338.2013.784467

Schumacker, R. E., \& Lomax, R. G. (2004). A beginner's guide to structural equation modeling (2nd ed.). Mahwah, NJ: Lawrence Erlbaum Associates. https://doi.org/10.4324/9781410610904

Smedley, J. (2009). Modelling personal knowledge management. OR Insight, 22(4), 221-233. https://doi.org/10.1057/ori.2009.11

Sondari, M. C. (2013). Personal knowledge management 2.0. International Journal of Social Science and 
Humanity, 3(4), 426-428. https://doi.org/10.7763/IJSSH.2013.V3.275

Steiger, J. H. (2007). Understanding the limitations of global fit assessment in structural equation modeling. Personality and Individual Differences, 42(5), 893-898. https://doi.org/10.1016/j.paid.2006.09.017

Tuksino, P. (2009). A quality assessment of science instructional Management in Basic Education Schools: An application of a value-added model and differential item functioning. (Unpublished Ph.D dissertation). Chulalongkorn University, Thailand.

Ullman, J. B. (2001). Structural equation modelling. In B. G. Tabachnick \& L. S. Fidell (Eds.), Using Multivariate Statistics (4th ed \& pp 653- 771). Needham Heights, MA: Allyn \& Bacon.

\section{Copyrights}

Copyright for this article is retained by the author(s), with first publication rights granted to the journal.

This is an open-access article distributed under the terms and conditions of the Creative Commons Attribution license (http://creativecommons.org/licenses/by/4.0/). 